\title{
Clinical phenotype in patients with $\alpha$-synuclein Parkinson's disease living in Greece in comparison with patients with sporadic Parkinson's disease
}

S Papapetropoulos, C Paschalis, A Athanassiadou, A Papadimitriou, J Ellul, M H Polymeropoulos, Th Papapetropoulos

\begin{abstract}
Objective-An Ala53Thr mutation of the $\alpha$-synuclein gene has been recently identified as a rare cause of autosomal Parkinson's disease (PD). The clinical characteristics of 15 patients with PD living in Greece with the Ala53Thr $\alpha$-synuclein mutation ( $\alpha$-synPD) were compared with patients with sporadic Parkinson's disease (sPD).

Methods-An investigator, blind to the results of the genetic analysis, examined 15 patients with $\alpha$-synPD and 52 consecutive patients with SPD. Demographic data, age at onset of the illness, modality of presentation, and duration of PD were collected. The unified Parkinson's disease rating scale, the Hoehn and Yahr scale, and the Schwab-England scale were completed. The patients with $\alpha$-synPD were matched for duration of disease with 32 of the 52 patients with sporadic PD (MsPD group). Results-Patients with the $\alpha$-synuclein mutation were significantly younger (mean 7.6 years), showed the first sign of the disease significantly earlier in life (mean 10.8 years), and had significantly longer duration of the disease compared with patients with sPD. Tremor at onset of the disease was present in only one $(6.7 \%)$ of the patients with $\alpha-\operatorname{syn} P D$, whereas it was present in $32(61.5 \%)$ of the patients with SPD $(p=0.0006)$. During the course of the disease one patient in the $\alpha$-synPD group went on to develop tremor compared with six patients in the SPD group. Rigidity, bradykinesia, postural instability, orthostatic hypotension, intellectual impairment, depression, complications of therapy, and clinical severity of the disease at the time of examination did not differ significantly between patients with $\alpha$-synPD and those with SPD, or between patients with $\alpha$-synPD and the MsPD group.
\end{abstract}

Conclusion-The younger age at onset of the illness, the much lower prevalence of tremor, and the longer duration of the disease characterise the clinical phenotype in this sample of patients with $\alpha$-synPD. The other symptoms and signs of the illness did not seem to differentiate the patients with $\alpha$-synPD from those with sPD. (f Neurol Neurosurg Psychiatry 2001;70:662-665)

Keywords: $\alpha$-synuclein Parkinson's disease; sporadic Parkinson's disease; familial Parkinson's disease
Recently two missense mutations in the $\alpha$-synuclein gene situated in chromosome 4, were reported as a rare cause of familial Parkinson's disease (PD) with autosomal dominant inheritance. The first mutation was a G209A substitution in the exon 4 of the gene resulting in Ala53Thr mutation of $\alpha$-synuclein. This mutation was first identified in a large Italian kindred and in three unrelated Greek families. ${ }^{1}$ Later it was reported in seven more Greek families ${ }^{2-4}$ and in one Greek-American kindred. ${ }^{5}{ }^{6}$ The second mutation was a G88C substitution in exon 3 of $\alpha$-synuclein gene resulting in an Ala30Pro mutation and it was detected in one affected member of a family of German origin. $^{7}$

We set out to study the clinical characteristics of 15 patients with PD with an Ala53Thr $\alpha$-synuclein mutation ( $\alpha$-synPD), living in Greece, and to compare them with patients with sporadic PD (sPD).

\section{Patients and methods}

During the period between February 1997 and July 1999 we studied 15 patients affected by $\alpha$-synPD, recruited from 10 Greek families. The molecular genetic analysis of these patients was carried out according to the procedures described by Athanassiadou et al. ${ }^{3}$ All 10 families were apparently unrelated ${ }^{2-4}$; however, a founder effect (coancestry) could not be excluded. Seven of these families originated from three different counties of northern Peloponnese in Greece. One family originated from south west Peloponnese and the remaining two families from different villages of north west Greece.

During the same period 52 consecutive patients with sPD were recruited from our outpatient clinic. All patients with PD were diagnosed through self presentation to senior neurologists using the Parkinson's Disease Society brain bank diagnostic criteria. ${ }^{8}$ Brain imaging and biochemical blood testing were used to exclude other causes of parkinsonism. None of the patients with SPD were found to carry the Ala53Thr mutation.

An informal interview was carried out in all patients and their families by one of the authors (SP), who was blind to the results of the genetic analysis. Demographic data, age at onset of the illness, modality of presentation, and duration of PD were collected. The unified Parkinson's disease rating scale (UPDRS), ${ }^{9}$ and the Hoehn and $\mathrm{Yahr}^{10}$ and Schwab-England ${ }^{11}$ scales were completed during the clinical examination. At 
Table 1 Clinical characteristics of subjects carrying the a-synuclein mutation, the total number of affected members in each family, and the number of the recalled generation in each family

\begin{tabular}{|c|c|c|c|c|c|c|}
\hline Greek family & Age of onset $(y)$ & $\begin{array}{l}\text { Duration of disease } \\
(y)\end{array}$ & $\begin{array}{l}\text { Presenting } \\
\text { complaint }\end{array}$ & $\begin{array}{l}\text { Dyskinesias on } \\
\text { examination }\end{array}$ & $\begin{array}{l}\text { Total affected } \\
\text { members in each } \\
\text { family }(n)\end{array}$ & $\begin{array}{l}\text { Recalled } \\
\text { generations (n) }\end{array}$ \\
\hline PDGR1 & 53 & 7 & Bradykinesia & Present & 6 & 4 \\
\hline PDGR2 & 51 & 2 & Bradykinesia & Present & 4 & 4 \\
\hline PDGR5 & 35 & 6 & Bradykinesia & Present & 9 & 5 \\
\hline PDGR5 & 62 & 9 & Rigidity & Absent & & \\
\hline PDGR8 & 53 & 3 & Rigidity & Absent & 7 & 5 \\
\hline PDGR8 & 43 & 7 & Rigidity & Present & & \\
\hline PDGR11 & 51 & 8 & Rigidity & Present & 10 & 4 \\
\hline PDGR11 & 49 & 11 & Rigidity & Present & & \\
\hline PDGR15 & 62 & 16 & Rigidity & Present & 3 & 3 \\
\hline PDGR18 & 58 & 4 & Rigidity & Present & 4 & 4 \\
\hline PDGR27 & 43 & 19 & Rigidity & Absent & 8 & 4 \\
\hline PDGR27 & 42 & 16 & Bradykinesia & Absent & & \\
\hline PDGR29 & 64 & 19 & Tremor & Absent & 4 & 3 \\
\hline PDGR30 & 25 & 17 & Rigidity & Absent & 7 & 3 \\
\hline PDGR30 & 27 & 17 & Rigidity & Absent & & \\
\hline
\end{tabular}

the time of the clinical examination patients were following the best medical treatment (all patients were taking levodopa, and were responding satisfactorily).

Comparisons were made between the patients with $\alpha$-synPD and all patients with sPD using the above mentioned rating scales. The difference in the duration of the disease between the patients with $\alpha$-synPD and those with sPD would have not allowed meaningful comparisons of clinical severity; therefore, the 15 patients with $\alpha$-synPD were matched $( \pm 2$ years) for duration of disease with 32 of the 52 patients with sPD (the MsPD group). The duration of the disease of the patients with $\alpha$-synPD was also compared with the duration of the disease of the 37 patients with younger onset sPD (YsPD group). The scores taken during on periods have been used in the comparisons for those patients who were known to have on-off episodes.
A Mann-Whitney $U$ test for two samples was used in non-parametric comparisons, and $\chi^{2}$ tests with Yates' corrected $\mathrm{p}$ value and two tailed Fischer exact $\mathrm{p}$ values in the comparison of proportions. The ethics committee of the University Hospital of Patras approved this study.

\section{Results}

The clinical characteristics of those carrying the $\alpha$-synuclein mutation are shown in table 1 . Table 2 shows that the patients with $\alpha$-synPD were significantly younger (mean 57.8 (SD 12) years), showed the first sign of the disease significantly earlier in life (mean 47.9 (SD 12.1) years), and had significantly longer disease duration (mean 10.7 (SD 6.1) years) compared with patients with sPD (mean 65.4 (SD 12) years, mean 58.7 (SD 13.3) years, and mean 6.1 (SD 5.5) years respectively). The sex ratio

Table 2 Sex, age, age at onset, and duration of disease in a-synPD, sPD, MsPD, and YsPD groups

\begin{tabular}{llllllll}
\hline & $\begin{array}{l}a-s y n P D \\
(n=15)\end{array}$ & $\begin{array}{l}s P D \\
(n=52)\end{array}$ & $p_{1}$ & $\begin{array}{l}M s P D \\
(n=32)\end{array}$ & $p_{2}$ & $\begin{array}{l}Y s P D \\
(n=37)\end{array}$ & $p_{3}$ \\
\hline Mean age (SD) & $57.8(12.0)$ & $65.4(12.5)$ & $0.02^{\star}$ & $63.1(11.6)$ & $0.07^{\star}$ & $60.2(10.5)$ & $0.21^{\star}$ \\
Sex: number of females (\%) & $6(40 \%)$ & $25(48 \%)$ & $0.8 \dagger$ & $14(43.8 \%)$ & $0.9 \dagger$ & $20(54.1 \%)$ & $0.54 \dagger$ \\
Mean age at onset (y (SD)) & $47.9(12.1)$ & $58.7(13.3)$ & $0.010^{\star}$ & $54.3(11.0)$ & $0.1^{\star}$ & $52.4(9.5)$ & $0.24^{\star}$ \\
Mean duration of PD (y (SD)) & $10.7(6.1)$ & $6.1(5.5)$ & $0.008^{\star}$ & $9.0(5.1)$ & $0.45^{\star}$ & $7.0(5.8)$ & $0.046^{\star}$
\end{tabular}

$\alpha$-synPD=Parkinson's disease (PD) patients with the $\alpha$-synuclein gene mutation; $\mathrm{PPD}=$ sporadic Parkinson's disease; $\mathrm{MsPD}=$ matched sporadic $\mathrm{PD}$ patients to $\alpha$-synPD patients for duration of disease; YsPD=younger onset sporadic PD patients; $\mathrm{p}_{1}=$ comparison between $\alpha$-synPD and sPD; $\mathrm{p}_{2}=$ comparison between $\alpha$-synPD and MsPD; $\mathrm{p}_{3}=$ comparison between $\alpha$-synPD and YsPD.

${ }^{\star}$ Mann-Whitney test; †Yates' corrected p value.

Table 3 Symptoms and signs at onset of disease and on examination in $\alpha$-synPD, sPD, and MsPD patients

\begin{tabular}{llllll}
\hline & $a-s y n P D(n=15)$ & $s P D(n=52)$ & $p_{1}$ & $M s P D(n=32)$ & $p_{2}$ \\
\hline $\begin{array}{l}\text { Symptoms and signs at onset of disease: } \\
\text { Tremor }\end{array}$ & $1(6.7)$ & $32(61.5)$ & & $17(53.1)$ & $0.0063 \dagger^{\star}$ \\
$\quad$ Rigidity & $10(66.7)$ & $16(30.8)$ & $0.0006 \dagger^{\star}$ & $12(37.5)$ & $3(9.4)$ \\
$\quad$ Bradykinesia & $4(26.7)$ & $4(7.7)$ & & & \\
Symptoms and signs on examination: & $2(13.3)$ & $38(73.5)$ & $0.0001^{\star}$ & $22(68.8)$ & $0.001^{\star}$ \\
$\quad$ Tremor & $14(93.3)$ & $45(86.5)$ & $0.67 \ddagger$ & $27(84.4)$ & $0.65 \ddagger$ \\
$\quad$ Rigidity & $11(73.3)$ & $23(44.2)$ & $0.09^{\star}$ & $17(53.1)$ & $0.3^{\star}$ \\
Bradykinesia & $8(53.3)$ & $23(44.2)$ & $0.74^{\star}$ & $17(53.1)$ & $0.76^{\star}$ \\
Postural instability & $3(20.0)$ & $5(9.6)$ & $0.36 \ddagger$ & $3(9.4)$ & $0.37 \ddagger$ \\
Orthostatic hypotension & $4(26.6)$ & $10(19.2)$ & $0.50 \ddagger$ & $8(25.0)$ & $1.0 \ddagger$ \\
Intellectual impairment & $8(53.3)$ & $24(46.2)$ & $0.84^{\star}$ & $15(46.9)$ & $0.92^{\star \star}$ \\
Depression & & &
\end{tabular}

Values are No of patients (\%). $\alpha$-synPD=Parkinson's disease (PD) patients with the $\alpha$-synuclein gene mutation; sPD=sporadic Parkinson's disease; $M s P D=$ matched sporadic PD patients to $\alpha$-synPD patients for duration of disease; $\mathrm{p}_{1}=$ comparison between $\alpha$-synPD and sPD; $\mathrm{p}_{2}=$ comparison between $\alpha$-synPD and MsPD.

*Yates' corrected p value.

†Rigidity and bradykinesia were combined in the rigid-akinetic variable for the comparison between groups.

$\ddagger 2$-tailed Fisher's exact test. 
Table 4 Mean scores (SD) of the unified Parkinson's disease rating scale (UPDRS), Hoehn and Yahr, and Schwab-England scales in a-synPD, sPD, and MsPD patients

\begin{tabular}{|c|c|c|c|c|c|}
\hline & $a-\operatorname{syn} P D(n=15)$ & $s P D(n=52)$ & $p_{1}$ & Ms $P D(n=32)$ & $p_{2}$ \\
\hline \multicolumn{6}{|l|}{ Four sections of UPDRS: } \\
\hline Mentation, behaviour, mood (UPDRS I) (maximum score 16) & $2.8(3.9)$ & $2.1(3.3)$ & 0.7 & $2.8(3.8)$ & 0.97 \\
\hline Activities of daily living (UPDRS II) (maximum score 52) & $21.5(14.7)$ & $13.3(9.6)$ & 0.075 & $16.7(10.3)$ & 0.38 \\
\hline Motor examination (UPDRS III) (maximum score 56) & $38.5(27.1)$ & $26.3(18.4)$ & 0.16 & $32.2(20.4)$ & 0.63 \\
\hline Complications of therapy (UPDRS IV) (maximum score 23) & $4.5(4.8)$ & $3.1(4.1)$ & 0.068 & $4.6(4.6)$ & 0.82 \\
\hline Total UPDRS score (maximum score 147 ) & $67.3(45.7)$ & $44.7(31.2)$ & 0.093 & $56.2(33.4)$ & 0.52 \\
\hline Hoehn and Yahr (staging $0-5$ ) & $3.1(1.2)$ & $2.4(1.1)$ & 0.024 & $2.8(1.1)$ & 0.30 \\
\hline Schwab-England ( $0-100 \%$ score) & $0.53(0.3)$ & $0.70(0.2)$ & 0.017 & $0.70(0.3)$ & 0.18 \\
\hline
\end{tabular}

$\alpha$-synPD=Parkinson's disease (PD) patients with the $\alpha$-synuclein gene mutation; MsPD $=$ matched sporadic PD patients to $\alpha$-synPD patients for duration of disease; $\mathrm{p}_{1}=$ comparison between $\alpha$-synPD and sPD; $\mathrm{p}_{2}=$ comparison between $\alpha$-synPD and MsPD (Mann-Whitney test).

did not differ significantly between the patients with $\alpha$-synPD and patients with sPD (table 2).

The clinical characteristics at the onset of the disease and at the time of clinical examination are shown in table 3 . Tremor at onset of the disease was present in only one $(6.7 \%)$ of the patients with $\alpha$-synPD, whereas it was present in $32(61.5 \%)$ of those with sPD. After matching for duration of the disease the difference in the proportion of patients with tremor at the time of the clinical examination between the patients with $\alpha$-synPD and the MsPD group remained significant. Table 3 also shows the significantly higher incidence of rigidity at disease onset in the $\alpha$-synPD group $(66.7 \%)$ compared with the sPD group (30.8\%).

The scores for the four sections of the UPDRS scale, as well as the scores of the overall assessment of clinical severity for $\alpha$-synPD, MsPD, and YsPD are shown in table 4.

\section{Discussion}

This study has shown that patients with $\alpha$-synPD were significantly younger and that their disease started significantly earlier in life compared with the patients with sPD. Early onset of the disease in other affected persons carrying the $\alpha$-synuclein mutation has previously been reported. ${ }^{6}{ }^{12}$ In the current study, the duration of the disease in the patients with $\alpha$-synPD was significantly longer than the duration of the disease of both SPD and YsPD groups. Longer duration of the disease was also found in the patients of the families reported by Golbe $e t a l^{12}$ and Markopoulou et al. ${ }^{6}$ Although all patients with PD in the present study were diagnosed through self presentation, the possibility of ascertainment bias in the early diagnosis in those with familial disorders should be noted, as this could give rise to a longer perceived course of disease.

Another finding in the present work was the lower prevalence of tremor in the patients with $\alpha$-synPD compared with the patients with sPD. During the course of the disease, the number of patients with tremor in both groups did not change significantly (table 3 ). Certainly in a group of patients with a very low prevalence of tremor and with a more akinetic-rigid presentation a less benign course of the disease would be expected. However, in the present study the overall clinical severity of the disease and the complications associated with treatment (dyskinesias and on-off fluctuations) did not differ significantly between patients with $\alpha$-synPD and MsPD group (table 4). Absence of tremor during the course of the disease was emphasised in the initial report presenting the Contursi family. ${ }^{13}$ However, when data (many historical) were more rigorously examined in 31 of the 60 affected members in the Contursi family, tremor was found in $58.1 \%$ of the patients. ${ }^{12}$ Of the 16 affected members in the Greek-American family, ${ }^{6}$ tremor at onset was found in two of the four patients who were clinically examined, whereas tremor during the course of the disease was reported in $68.8 \%$ of all patients in this family. In the current study, the very low incidence of tremor at disease onset, and thereafter during the course of the disease when compared with previously reported patients with $\alpha$-synPD living in the United States or Italy is difficult to explain. However, it could be speculated that the difference could be attributed to the influence of other environmental or genetic factors. The low incidence of tremor at disease onset in our patients with $\alpha$-synPD is unlikely to be attributable to study design as the incidence of tremor, on clinical examination during the course of the disease, was found to be almost unchanged.

The sex ratio in our patients with $\alpha$-synPD and those with sPD is similar to the sex ratio reported for idiopathic PD $(3: 2),{ }^{14}$ the Contursi family (3.7:2), ${ }^{13}$ and the Greek-American kindred (2.7:2). ${ }^{7}$ Apart from tremor, the other clinical symptoms and signs, including intellectual impairment and depression, did not differ between the $\alpha$-synPD and MsPD groups. Dementia and depression were also reported in other patients with PD with the $\alpha$-synuclein mutation ${ }^{6}{ }^{12}$ but this did not seem to characterise the phenotype of the disease. All patients in the $\alpha$-synPD and sPD groups in the present study were levodopa responders. Response to levodopa in patients with $\alpha$-synPD has also been reported in two other families. ${ }^{6}{ }^{12}$

Mutations in the $\alpha$-synuclein protein are a rare cause of $\mathrm{PD}$, as shown in studies of several hundred cases of familial PD in the United States, ${ }^{15-19}$ in Europe ${ }^{20-28}$ and elsewhere. ${ }^{29}$ The mutation of G209A in the $\alpha$-synuclein gene, which was not found in our patients with sPD, is also generally absent in patients with sporadic Parkinson's disease. ${ }^{30} 31$

The younger age of onset of the illness, the lower prevalence of tremor, and the longer duration of the disease characterise the clinical phenotype in this sample of patients with $\alpha$-synPD. The other symptoms of the illness did not seem to differentiate the patients with $\alpha$-synPD from those with sPD. A detailed study 
is currently underway to compare the 15 patients with $\alpha$-synPD with a large group of Greek patients with familial Parkinson's disease without the $\alpha$-synuclein gene mutation.

1 Polymeropoulos MH, Lavedan C, Leroy E, et al. Mutation in the $\alpha$-synuclein gene identified in families with

2 Papadimitriou A, Veletza V, Hadjigeorgiou GM, et al. Mutated $\alpha$-synuclein gene in two Greek kindreds with familial PD: Incomplete penetrance? Neurology 1999;52:651-4.

3 Athanassiadou A, Voutsinas G, Psiouri L, et al. Genetic analysis of families with Parkinson's disease that carry the Ala53Thr mutation in the gene encoding a-synuclein. $A m \mathcal{F}$ Hum Genet 1999;65:555-8.

4 Veletza S, Bostatzopoulou S, Hantzigeorgiou G, et al. $\alpha$-Synuclein mutation associated with familial Parkinson's disease in two new Greek kindred. 7 Neurol 1999;246(supp 1): $1-43$.

5 Markopoulou K, Wszolek ZK, Pfeiffer RF, et al. Reduced expression of the G209A $\alpha$-synuclein allele in familial parexpression of the G209A $\alpha$-synuclein al
kinsonism. Ann Neurol 1999;46:374-81.

6 Markopoulou K, Wszolek ZK, Pfeiffer RF. A GreekAmerican kindred with autosomal dominant, levodopa-
responsive parkinsonism and anticipation. Ann Neurol responsive park

7 Krüger R, Kühn W, Müller T, et al. Ala30Pro mutation in the gene encoding alpha-synuclein in Parkinson's disease [letter]. Nat Genet 1998;18:106-8.

8 Hughes AJ, Daniel SE, Kilford, et al. Accuracy of clinical diagnosis of idiopathic Parkinson's disease: a clinicopathological study of 100 cases. $\mathcal{F}$ Neurol Neurosurg Psychiatry 1992;55:181-4.

9 Fahn S, Elton RL, Members of the UPDRS Development Committee. Unified Parkinson's disease rating scale. In: Fahn S, Marsden CD, Goldstein M, et al, eds. Recent developments in Parkinson's disease. Vol II New Jersey: Macmillan Healthcare Information, 1987:153-63.

10 Hoehn MM, Yahr MD. Parkinsonism: onset, progression and mortality. Neurology 1967;17:427-42.

11 Schwab RS, England AC. Projection technique for evaluating surgery in Parkinson's disease. In: FJ Gillingham, IML ing surgery in Parkinson's disease. In: FJ Gillingham, IML Donaldson, eds. Third symposium on

12 Golbe LI, Di Iorio G, Sanges G, et al. Clinical genetic analysis of Parkinson's disease in the Contursi kindred. Ann Neurol 1996;40:767-75.

13 Golbe LI, Di Iorio G, Bonarita V, et al. A large kindred with autosomal dominant Parkinson's disease. Ann Neurol 1990 27:276-82.

14 Waters CH. Diagnosis and management of Parkinson's disease. USA: Professional Communications, 1998:17.

15 Chan P, Jiang X, Forno LS, et al. Absence of mutations in the coding region of the $\alpha$-synuclein gene in pathologically proven Parkinson's disease. Neurology 1998;50:1136-7.

16 Farrer M, Wavrant-De Vrieze F, Crook R, et al. Low frequency of $\alpha$-synuclein mutations in familial Parkinson's disease. Ann Neurol 1998;43:394-7.
17 Parsian A, Racette B, Zhang ZH, et al. Mutation sequence analysis, and association studies of $\alpha$-synuclein in Parkinson's disease. Neurology 1998;51:1757-9.

18 Chan $\mathrm{P}$, Tanner CM, Jiang X, et al. Failure to find the $\alpha$-synuclein gene missence mutation (G209A) in 100 patients with younger onset Parkinson's disease. Neurology 1998;50:513-4.

19 Wang WW, Khajavi M, Patel BJ, et al. The G209A mutation in the $\alpha$-synuclein gene is not detected in familial cases of Parkinson's disease in non-Greek and/or non-Italian populations. Arch Neurol 1998,55:1521-3.

20 Muíoz E, Oliva R, Obach V, et al. Identification of Spanish familial Parkinson's disease and screening for the Ala53Thr mutation of the $\alpha$-synuclein gene in early onset patients. Neurosci Lett 1997;235:57-60.

21 Bennett P, Nicholl DJ. Absence of the G209A mutation in the $\alpha$-synuclein gene in British families with Parkinson's disease. Neurology 1998;50:1183.

22 Vaughan JR, Farrer MJ, Wszolek ZK, et al. Sequencing of the $\alpha$-synuclein gene in a large series of cases of familial Parkinson's disease fails to reveal any further mutation. Hum Mol Genet 1998;7:751-3.

23 Zareparsi S, Kaye J, Camicioli R, et al. Analysis of the $\alpha$-synuclein G209A mutation in familial Parkinson's disease. Lancet 1998;351:37-8.

24 Autere J, Hitunen M, Mannermaa A, et al. Sequence analysis of $\alpha$-synuclein gene in familial Parkinson's disease in Finland. Eur f Neurol 1999;6(suppl 3):82-3.

25 Bonifati V, Vaughan JR, Fabrizio E, et al. The Italian Parkinson Genetics Study Group and European Consortium on Genetic Susceptibility in Parkinson's disease. A screening for Ala53Thr mutation in alpha-synuclein gene in Italian families with Parkinson's disease. F Neurol 1999;246(suppl 1):1-169.

26 Lucotte G, Mercier G, Turpin JC. Lack of mutation G209A in the $\alpha$-synuclein gene in French patients with familial and sporadic Parkinson's disease [letter]. F Neurol Neurosurg Psychiatry 1998;60:948-9.

27 Vaughan J, Durr A, Tassin J, et al. The $\alpha$-synuclein Ala53Thr mutation is not a common cause of familial Parkinson's disease: a study of 230 European cases. European Consortium on Genetic Susceptibility in Parkinson's disease. Ann Neurol 1998;44:270-3.

28 Vaughan JR, Farrer MJ, Wszolek ZK, et al. Sequencing of the $\alpha$-synuclein in a large series of cases of familial Parkinson's disease fails to reveal any futher mutations. European Consortium on Genetic Susceptibility in Parkinson's disease. Hum Mol Genetics 1998;7:751-3.

29 Ho SL, Kung MH. G209A mutation in the $\alpha$-synuclein gene is rare and not associated with sporadic Parkinson's disease. Mov Disord 1998;13:970-1.

$30 \mathrm{Hu}$ CJ, Sung SM, Liu H, et al. No mutation of G209A in the alpha-synuclein gene in sporadic Parkinson's disease among Taiwan Chinese. Eur Neurol 1999;41:85-7.

31 Gasser T. Genetic of Parkinson's disease. Ann Neurol 1998; 44(suppl 1):553-7. 